\title{
PENGELOLAAN PEMBELAJARAN BERBASIS PENDEKATAN BEYOND CENTERS AND CIRCLE TIME (BCCT) PADA ANAK PLAYGROUP DI SEKOLAH ALAM BOSOWA
}

\author{
NURRAHMATILLAH, ARIFUDDIN SIRA, A.NUR MAULANA \\ Universitas Islam Negeri Alauddin Makassar \\ E-mail: thylaangelz2@gmail.com
}

\begin{abstract}
:
This research aims to know learning management in the early childhood Bosowa Alam school with the BCCT approach. The previous main problem to be listed into a number of subproblems, namely 1) What kind of learning resources used in early childhood in the Bosowa Alam school? 2) How to manage learning toward early childhood education at Bosowa Nature School by applying BCCT and DAP? This research classified as qualitative with employing pedagogical and psychological approach. The data was taken from head master, class Guardian, Teachers and students. The data collection methods used observation, interviews, documentation, and some referencea. Techniques of data analysis carried out in three stages, namely data reduction, data presentation and conclusion collection. The results of this study indicate the fact that several things must be highly considered by educators before formulating a learning plan that will be used in early childhood of bosowa natural school. The implementation of learning supported by learning resources used in each center to be developed with 5 child domains (affection, language, cognition, social and psychomotor) and 7 multiple intelligences (logical-mathematical intelligence, Sapatial intelligence, musical intelligence, kinesthetic intelligence, Interpersonal and Intrapersonal intelligence). The management of Bosowa Alam school learning resources carried out in 5 stages: students identification, planning learning resources, preparing learning resources, using learning resources as well and evaluation methods.
\end{abstract}

Keywords: Learning Management, Beyond Center and Circle Time (BCC)

\section{PENDAHULUAN}

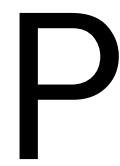

endidikan usia dini sangatlah penting untuk dilakukan. Hal tersebut akan menjadi dasar bagi pembentukan kepribadian pada masa yang akan datang.

Pendidikan usia dini tidak hanya dilakukan pada saat anak lahir tapi juga pada saat sebelum adanya janin dan pada saat anak dalam kandungan. Dalam alquran ada banyak ayat yang menyerukan keharusan orang tua untuk selalu menjaga dan mendidik seluruh anak-anaknya, termasuk anak yang masih dalam kandungannya.

Anak usia dini berusia sejak lahir sampai dengan usia delapan tahun (Bredekamp, 1987:123). Usia lahir sampai memasuki pendidikan dasar merupakan masa keemasan sekaligus masa kritis dalam tahapan kehidupan yang akan menentukan tahapan perkembangan anak selanjutnya (Mansur, 2015: 18). 
Undang Undang RI No. 20 Tahun 2003 tentang Sistem Pendidikan Nasional juga menjelaskan bahwa pendidikan anak usia dini adalah suatu upaya yang ditujukan kepada anak sejak lahir sampai dengan usia enam tahun yang dilakukan melalui pemberian rangsangan pendidikan untuk membantu pertumbuhan dan perkembangan jasmani dan rohani agar anak memiliki kesiapan dalam memasuki pendidikan lebih lanjut.

Dalam kegiatan proses belajar ada hubungan antara stimulus dengan respon yang tepat melalui trials and errors (Thorndik, 2000:15). Pemberian stimulus diberikan sesuai dengan karekteristik perkembangan setiap anak, sehingga dapat berkembang secara maksimal

Setiap tahap perlu dialami oleh setiap anak, sehingga anak mempunyai pengalaman yang cukup sebelum pindah ke tahap selanjutnya. Stimulus yang diberikan pada setiap tahap sangat berpengaruh pada perkembangan anak. Anak akan mengalami kesulitan ketika ada tahap yang tidak dilalui dengan tuntas.

Dalam pendidikan usia dini anak mulai diberikan stimulasi pendidikan dengan cara belajar melalui bermain secara terencana dan sistematis. Dengan bermain pendidik mampu memberikan stimulus dengan mudah yang menjadi target di usia perkembangannya. Namun, masih banyak yang keliru tentang proses pembelajaran pada tingkat usia dini seperti belajar dengan duduk tenang, tangan dilipat dan mendengarkan pendidik menjelaskan dan menyelesaikan tugus-tugas yang bahkan tugas tersebut dibawa diselesaikan di rumah (PR) serta, kurangnya pengetahuan dalam pengelolaan sumber belajar pada anak usia dini. Lembaga pendidikan anak usia dini dalam pembelajaran masih formal baca, tulis dan hitung, tanpa belajar melalui bermain sebenarnya hanya memenuhi tuntutan orang tua yang tidak menyadari urgensi bermain pada anak (Sidhahrtp, 2002:54).

Sumber belajar berperan dalam menyediakan berbagai informasi dan pengetahuan yang diperlukan dalam mengembangkan berbagai kompetensi yang diinginkan. Sumber belajar meliputi pesan, orang, bahan, alat, teknik dan latar (Yusufhadi, 2003: 77). Oleh karena itu, sumber belajar yang beraneka ragam, diantaranya berupa bahan media pembelajaran mampu memberikan kontribusi positif dalam peningkatan mutu pendidikan dan pembelajaran.

Beragamnya sumber belajar perlu juga menjadi perhatian bagaimana penggunaan sumber belajar yang tepat pada anak usia dini. Program pendidikan anak usia dini dalam pelaksanaannya dikenal berbagai macam pendekatan di antaranya Montessori, High Scope, Creative Curriculum, Project Base, and Beyond Centers and Circle time (BCCT). Dari berbagai pendekatan tersebut ada satu konsep yang dapat dijadikan sebagai acuan dalam penerapan proses pembelajaran anak usia dini. Dimana pendidikan tersebut menyenangkan, yaitu pendidikan yang sesuai dengan perkembangan anak. Konsep pendidikan yang sesuai dengan pendidikan anak tersebut biasa disebut dengan DAP. Pembelajaran yang sesuai dengan perkembangan peserta didik menempatkan peserta didik sebagai pusat 
pembelajaran, sehingga tidak hanya pendidik saja yang aktif dalam memberikan informasi, tetapi peseta didik juga terlibat aktif dalam mengeksplorasi dan menginvestigasi dunia dan lingkungannya.

Dengan memahami tahap perkembangan peserta didik mampu membantu pendidik dan orang tua untuk memahami mereka, merespon dengan tepat dan bereaksi sesuai kebutuhan peserta didik tanpa khawatir berlebihan. Pendekatan ini akan memberikan stimulus sesuai dengan perkembangan peserta didik. Oleh karena itu, kurikulum yang disiapkan harus berbeda-beda disebabkan peserta didik mememiliki keunikannya masing-masing. Kurikulum yang baik adalah kurikulum yang memenuhi kebutuhan peserta didik. Pendekatan ini berkaitan dengan sumber belajar yang digunakan. Dalam pemilihan sumber belajar sangat diperlukan ketelitian untuk memilih sumber pembelajaran yang sesuai dengan perkembangan peserta didik.

Berdasarkan uraian tersebut Beyond Center and Circle Time (BCCT) merupakan sebuah pendekatan yang berdasarkan konsep DAP. Hal ini dikarenakan Beyond Center and Circle Time (BCCT) dikembangkan berdasarkan hasil kajian teoritik dan pengalaman empirik oleh Creative Center for Chilhood Research and Training (CCRT) di Florida, USA.

Pendekatan BCCT memiliki standar operasional yang baku dimana dalam pelaksanaan pembelajaran pendidik selalu memberikan stimulus sebelum dan setelah melakukan kegiatan dalam posisi duduk dan melingkar serta pemilihan sumber belajar yang tepat serta pengolaan sumber belajar pada anak usia dini.

Pada sekolah tingkat usia dini masih banyak sekolah yang belum mampu merancang kurikulum yang sesuai dengan kebutuhan anak. Dalam merancang sebuah kurikulum sebaiknya melihat kebutuhan anak, agar apa yang ingin diberikan kepada anak tidak berlebihan. Berbeda ketika merancang suatu rencana pembelajaran yang mana merupakan hasil dari evaluasi apa yang dibutuhkan anak sebenarnya. Adapun kebutuhan anak usia dini dapat dinilai dari hasil evaluasi selama proses bermain berlangsung seperti mewarnai, menggambar, menyanyi, mengenal huruf, membaca dan menghitung. Berdasarkan hal tersebut kemudian dinilai apakah hal tersebut tepat untuk dilakukan dan sesuai kebutuhan anak atau tidak.

\section{KAIIAN PUSTAKA \\ Perencanaan Kurikulum}

Menurut Hamalik (1993:157), perencanaan kurikulum adalah suatu proses sosial yang kompleks yang menuntut berbagai jenis dan tingkat pembuatan keputusan. Tujuan perencanaan kurikulum ini dikembangkan dalam bentuk kerangka teori dan penelitian terhadap kekuatan sosial, pengembangan masyarakat, kebutuhan, dan gaya belajar siswa. Atas pertimbangan tujuan 
tersebut, penyelenggara pendidikan harus memahami jenis-jenis model perencanaan/desain kurikulum.

Adapun jenis-jenis model perencanaan/desain kurikulum adalah (1) Model Desain Kurikulum Humanistik, pendidikan diarahkan kepada membina manusia yang utuh bukan saja segi fisik dan intelektual tetapi juga segi sosial dan afektif (emosi, sikap, perasaan, nilai, dan lain-lain) (Sukmadinata, 2013:28); (2) Model Desain Kurikulum Sistemik yang menekankan keahlian dan kompetensi serta standar penampilan dimana pengajaran diajarkan keahlian tetapi tidak memberikan kesempatan yang menantang bagi siswa secara intelektual untuk mendapatkan konsep yang kuat pada disiplin ilmu tentang perkembangan ingkuirinya, dengan cara memberikan ruang gerak secara mendalam dalam suatu pembelajaran (McNeil, 2006:64); (3) Model Desain Kurikulum Subjek Akademik merupakan satu cermin dari tren budaya yang sangat luas, yang mengarahkan adanya modifikasi pendidikan dimana tren ini meletakkan ekonomi sebagai inti dan ilmu pengetahuan sebagai komoditas.

\section{Pengelolaan}

Menurut Hamiseno (2002:10), pengelolaan adalah substansi dari mengelola, sedangkan mengelola berarti suatu tindakan yang dimulai dari penyusunan data, merencanakan, mengorganisasikan, melaksanakan sampai dengan pengawasan dan penilaian. Berdasarkan pengertian ini dapat disimpulkan bahwa pengelolaan adalah suatu kegiatan untuk mengatur atau mengorganisasikan serta mengevaluasi suatu usaha untuk mencapai tujuan.

Di Indonesia pengertian anak usia playgroup ditujukan kepada anak yang berusia 3-4 tahun (Masnipal, 2013:78), seperti dalam Undang-Undang Republik Indonesia Nomor 20 Tahun 2003 tentang Sistem Pendidikan Nasional pada Pasal 1 Ayat 14 yang menyatakan pendidikan anak usia dini adalah pendidikan yang diperuntukkan bagi anak sejak lahir sampai usia 6 tahun (Aisyah, 2011:13).

\section{BCCT (Beyond Centers and Circle Time)}

BCCT merupakan pendekatan yang dikembangkan berdasarkan hasil kajian teoritik dan pengalaman empirik oleh Creative Center for Childhood Research and Training (CCCRT) di Florida USA, dan dilaksanakan di Creative Pre School Florida, USA selama lebih dari 25 tahun, baik untuk anak normal maupun untuk anak dengan kebutuhan khusus (Depdiknas, 2007). Proses pembelajaran BCCT berpusat di sentra main dan saat anak dalam lingkaran dengan menggunakan 4 jenis pijakan (scaffolding) untuk mendukung perkembangan anak, yaitu: (1) pijakan lingkungan main; (2) pijakan sebelum main; (3) pijakan selama main; dan (4) pijakan setelah main.

Metode ini juga memandang bermain sebagai media yang tepat dan satusatunya media pembelajaran anak, karena di samping menyenangkan, bermain dalam setting pendidikan dapat menjadi media untuk berfikir aktif dan kreatif. 
Pembelajaran yang berpusat pada anak dan peran guru hanya sebagai fasilitator, motivator dan evaluator merupakan ciri dari metode BCCT ini. Kegiatan anak juga berpusat pada sentra-sentra main yang berfungsi sebagai pusat minat yang memiliki standar operasional prosedur yang baku dan memiliki pijakan-pijakan dalam proses pembelajarannya.

Prinsip Beyond Center and Circle Time (BCCT) antara lain menurut Yunus (2009): (1) keseluruhan proses pembelajarannya berlandaskan pada teori dan pengalaman empirik; (2) setiap proses pembelajaran ditujukan untuk merangsang seluruh aspek kecerdasan anak (kecerdasan jamak) melalui bermain terencana dan terarah serta dukungan pendidik dalam bentuk pijakan-pijakan; (3) menempatkan penataan lingkungan main sebagai pijakan awal yang merangsang anak untuk aktif, kreatif dan terus berpikir dengan menggali dan menemukan pengalamannya sendiri; (4) menggunakan standar operasional yang baku dalam proses pembelajarannya; (5) mensyaratkan pendidik dan pengelola program untuk mengikuti pelatihan sebelum menerapkan pendekatan ini; (6) melibatkan orangtua dan keluarga sebagai satu kesatuan proses pembelajaran untuk mendukung kegiatan anak di rumah; (7) selama anak berada di sentra, pendidik secara bergilir memberikan pijakan kepada setiap anak; (8) pendidik bersama anak membereskan peralatan dan tempat main; (9) pendidik memberikan waktu kepada anak untuk ke kamar kecil dan minum secara bergiliran; (10) pendidik dan anak duduk dalam lingkaran untuk memberikan pijakan pengalaman setelah main; (11) pendidik bersama anak makan bekal yang dibawanya (tidak dalam posisi istirahat); (12) kegiatan penutup; (13) anak-anak pulang secara bergilir.

\section{METODE PENELITIAN}

Penelitian ini menggunakan metode kualitatif dan data yang dikumpulkan pada penelitian ini adalah data yang menggambarkan proses pengelolaan sumber belajar dengan sasaran utama aktivitas pendidik dalam melaksanakan pembelajaran dari proses persiapan yang meliputi penataan lingkungan main, penyambutan anak dan pijakan sebelum main, pijakan saat main serta pijakan setelah main. Dalam penelitian ini peneliti menentukan 2 orang pendidik dan 1 orang pengelola sebagai informan. Data yang dikumpulkan dalam penelitian ini adalah informasi, kegiatan, situasi pembelajaran, dokumentasi dan peristiwaperistiwa yang terjadi pada waktu observasi. Adapun lokasi penelitian ini adalah Sekolah Alam Bosowa yang berada di Jalan Manunggal Tanjung Bunga kecamatan Maccini. Sekolah Alam Bosowa adalah sekolah tingkat PG, TK dan SD yang berada di Tanjung Bunga Kota Makassar. Peserta didik yang berada di Sekolah Alam Bosowa berasal dari berbagai wilayah yang ada di Kota Makassar. Sekolah Alam Bosowa memiliki karakteristik yang menarik untuk dijadikan kajian penelitian seperti lokasi dan kurikulum yang diterapkan. Selain itu, Sekolah Alam Bosowa 
menerapkan pengelolaan sumber belajar dengan pendekatan BCCT dan DAP dalam pelaksanaan di setiap kegiatan.

Metode pengumpulan data dilakukan dengan observasi, wawancara, angket, dokumentasi, dan gabungan keempatnya. Sumber data yang digunakan adalah primer dan sekunder.

\section{HASIL PENELITIAN DAN PEMBAHASAN}

\section{Perencanaan Pembelajaran Anak Playgroup Sekolah Alam Bosowa}

Dalam proses Perencanaan di Sekolah Alam Bosowa yang menganut metode pembelajaran BCCT selalu mengacu kepada komponen kurikulum yang berlandaskan curricular domain, kelima domain ini sangat penting untuk tahap perkembangan anak, karena merupakan acuan untuk merencanakan programprogram pembelajaran yang dibutuhkan oleh anak berdasarkan evaluasi di tahun sebelumnya.

\section{Pelaksanaan Pembelajaran Sekolah Alam Bosowa}

Metode Penggunaan sumber belajar yang digunakan pada anak usia dini di Sekolah Alam Bosowa didasarkan pada tahap perkembangan anak usia dini yang bisa didapatkan di beberapa sentra yang telah disiapkan. Tingkat PG-TK terdapat lima sentra yaitu sentra bahan alam, sentra main peran (makro dan mikro), sentra seni, sentra balok dan sentra persiapan. Tingkat SD terdapat lima sentra yakni sentra bahasa, sentra matematika, sentra drama, sentra sains dan sentra seni.

\section{Hasil evaluasi pembelajaran Sekolah Alam Bosowa}

Evaluasi hasil belajar di Sekolah Alam Bosowa merupakan suatu proses yang dilakukan untuk mengetahui tingkat kinerja akademik. Evaluasi hasil belajar dilakukan secara menyeluruh dan berkelanjutan dengan cara yang sesuai dengan ciri-ciri pendidikan keahlian yang bersangkutan.

Sekolah Alam Bosowa adalah sekolah yang mengevaluasi anak secara individu yang mana anak di review perorangan di tiap sentra. Setiap guru sentra mempersiapkan evaluasi enam domain yang mana keenam domain tersebut dikumpulkan pada wali kelas per kelompok yang akhirnya dituliskan dalam webbing evaluasi individu dan webbing evaluasi kelompok.

Berikut adalah beberapa tahapan evaluasi peserta didik di Sekolah Alam Bosowa.

\section{Webbing Evaluasi Individu}

Kegiatan ini dilakukan di akhir semester untuk melihat perkembangan anak secara individu, Laporan bisa ditulis dalam bentuk narasi atau dalam bentuk webbing.

Adapun di dalam evaluasi individu terdapat beberapa poin penting seperti: (a) catatan anekdot; (b) evaluasi harian; (c) evaluasi hasil karya; (d) kompilasi data; dan (e) buku rapor. 


\section{Webbing Evaluasi Kelompok}

Setelah melakukan evaluasi individu kegiatan selanjutnya adalah mengevaluasi secara kelompok. Kelompok yang dimaksud adalah tingkatan kelas, Hal ini dilakukan untuk melihat seberapa banyak target yang telah rencanakan di semester sebelumnya sama halnya dengan evaluasi individu. Evaluasi kelompok juga bisa dituliskan dalam bentuk narasi maupun dalam bentuk webbing.

\section{Webbing Materi Individu}

Webbing ini dilakukan untuk menentukan materi apa saja yang diperlukan untuk membantu dan mengembangkan pengetahuan anak didik sesuai evaluasi yang telah di lakukan.

\section{Theme Storming}

Kegiatan ini adalah mengumpulkan semua kosa kata yang berhubungan dengan materi, sehingga dapat dilihat kata apa saja yang sering muncul untuk kemudian dijadikan sebagai kumpulan tema.

\section{Webbing Tema}

Kegiatan ini merangkum semua tema yang akan dilakukan selama setahun dalam bentuk webbing.

Setelah kelima tahapan evaluasi terselesaikan, maka akan muncullah tema tema baru yang sesuai dengan tahap perkembangan anak didik. Adapun materimateri dan tema yang diberikan adalah materi yang benar-benar dibutuhkan oleh peserta didik berdasarkan dari hasil evaluasi yang telah dilakukan

\section{PENUTUP/SIMPULAN}

Berdasarkan dari temuan hasil yang diperoleh, maka dapat disimpulkan beberapa poin sebagai berikut: (1) perencanaan kurikulum yang digunakan pada tingkat pendidikan anak usia dini Sekolah Alam Bosowa dengan pendekatan BCCT dan DAP digunakan berdasarkan kebutuhan peserta didik atau sesuai dengan tahapan perkembangan peserta didik. Sumber belajar yang digunakan membantu peserta didik melalui tahapan main yaitu main simbolik, main peran, dan main pembangunan. Sumber belajar yang digunakan bertujuan untuk membangun afeksi, kognisi, bahasa, sosial dan psikomotor peserta didik; (2) pelaksanaan kurikulum di Sekolah Alam Bosowa melalui pendekatan DAP dan BCCT yang disinkronkan dengan kurikulum K13 sesuai peraturan DIKNAS dan PERMEN 137 dan 146; (3) penerapan BCCT dan DAP melalui beberapa pijakan yaitu pijakan sebelum main, pijakan saat bermain dan pijakan setelah bermain.

\section{DAFTAR PUSTAKA}

Aisyah, Siti. et.al. (2011). Perkembangan dan Konsep Dasar Pengembangan Anak Usia Dini. Jakarta: UniversitasTerbuka. 
Bredekamp. (1987). NAEYC National Accosiation Education for Young Children.

Depdiknas. (2007). Pedoman Penerapan PendekatanBeyond Centres and Circle Time (BCCT). (Pendekatan Sentra dan Saat Lingkaran) dalam Pendidikan Anak Usia Dini. Jakarta

Hamalik, Oemar. (1993). Model-model Pengembangan Kurikulum.Bandung: PPs Universitas Pendidikan Indonesia.

Hamiseno, Winarno. (2002). Manajemen Umum. Jakarta: Ciputat Pers.

Mansur. (2015). Pendidikan Anak Usia Dini. Yogyakarta: Pustaka Pelajar.

Masnipal. (2013). Siap Menjadi Guru dan Pengelola PAUD Profesional.Jakarta: Elex Media Komputindo.

McNeil, John D. (2006). Contenporery Curiculum. London: Wiley \& Sons Inc.

Sidhahrtp, Suryati. (2002). Pendekatan dalam Pendidikan Anak Usia Dini. Yogyakarta: Lembaga Penelitian Universitas Negri.

Sukmadinata, Nana Syaodih. (2013). Pengembangan Kurikulum, Teori dan Praktek. Bandung: Rosdakarya.

Yusufhadi, Miarso. (2003). Menyemai Benih Teknologi Pendidikan. Jakarta : Pernada Media.

Yunus, Abidin. (2009). Bermain pengantar bagi penerapan pendekatan Beyond Centers and Circle Time (BCCT) dalam dimensi PAUD. 